\title{
ELIMINASI OSILASI DAN PENCAPAIAN WAKTU KESTABILAN TERCEPAT TURBIN ANGIN BERBASIS TIGA INPUT FUNGSI KEANGGOTAAN LOGIKA FUZZY KONTROLER
}

\author{
Rony HR Fora ${ }^{1)}$ dan Widodo ${ }^{1)}$ \\ 1), Prodi Teknik Elektro; Fakultas Teknologi Industri \\ Universitas PGRI Adibuana Surabaya \\ Email: ronifora@yahoo.co.id
}

\begin{abstract}
Abstrak
Strategi kontrol mendapatkan perhatian yang meluas dari para periset sistem kontrol. Salah satu yang sangat penting dari strategi kontrol adalah aksi kontrol. Kontroler mendapatkan tugas utama mempertahankan kestabilan sistem, dan untuk mempertahankan kestabilan sistem tergantung dari aksi kontrol yang dilakukan. Aksi kontrol menentuan kapabilitas kontroler untuk mengkondisikan keadaan menjadi stabil. Perilaku respon dinamik untuk mengatur kondisi yang diinginkan biasanya ditunjukkan dengan riple dan beberapa waktu yang dibutuhkan untu mencapai kondisi stabil. Tiga input fungsi eanggotaan metode fuzzy logic kontroler bisa menyelesaikan permasalahan riple dan membutuhkan waktu lebih singkat untuk mencapai kestabilan atau sering dierbut settling time. Metode ini lebih baik daripada dua input fungsi keanggotaan. Dengan mengikombinasikan dengan adaptif fungsi output.
\end{abstract}

Kata kunci: Eliminasi Osilasi, Waktu Kestabilan Tercepat, Tiga Fungsi Keanggotaan, Fuzzy Logic Kontroler

\section{Abstract}

The control strategy has gotten the emerged attention of the control researcher. One of the important of the control strategy is the control action. Controller has the duty to keep stable of the system, and how to keep is a matter depends of the control action. Control action determined the capability of controller to the set state condition. The behavior of dynamic response to set condition usually show the ripple and it need a several time to reach the stable condition which called settling time. Triple input membership function fuzzy logic controller method can overcome the ripple problem, to eliminated the ripple and also find the best settling time. This method is better than dual input membership function. With the combination of adaptive output membership function.

Keywords: Eliminated Ripple, The Best Time Settling, Triple Input Membership Function, Fuzzy Logic Controller 


\section{PENDAHULUAN}

Pengontrol biasanya digunakan dalam instrumentasi listrik yang membutuhkan nilai yang ditetapkan. Nilai yang ditempatkan di luar sini harus dikontrol dan sesegera mungkin untuk didukung untuk menetapkan nilai. Kondisi itu disebut sistem kestabilan. Perilaku data selama kondisi kestabilan menjadi pembahasan serius dan menarik untuk diteliti. Tujuan utamanya adalah bagaimana mencapai kondisi stabil sesegera mungkin. Sungguh, tidak mudah untuk dicapai sesegera mungkin. Jarang sekali, waktu yang sangat lama untuk mencapai tujuan itu atau sangat cepat mencapai tujuan tapi sangat banyak riak atau osilasi yang mengganggu sistem. Kondisi itu terjadi sangat lama dan hal itu menyebabkan beberapa ilmuwan berasumsi bahwa riak harus terjadi toleransi pada $2 \%$ sampai $5 \%$. Para periset bekerja dengan sepenuh hati untuk mengatasi riak itu Meski menemukan metode tindakan kontrol. Tindakan pengendalian tersebut diharapkan bisa memperbaiki kondisi riak. Promosi pertama tindakan pengendalian proporsional. Ogata mengenalkan metode ini dan masih ada riak, maka akan diperbaiki dengan kombinasi proporsional dengan integral (PI) dan proporsional menjadi integral turunan (PID) memberikan kontribusi dan riak masih tersedia. Ketiga metode tersebut kemudian biasanya disebut metode konvensional. Metode kedua adalah beberapa kombinasi aksi pengendalian konvensional dan perhitungan numerik yang diperkenalkan oleh beberapa ilmuwan. B. Boukhezzar, L. Lupu, H. Siguerdidjane, M. Handintroduced control action untuk aplikasi PID Controller dan kecepatan variabel LQG. Ying-Yi Hong, Shiue-Der Lu, Ching-Sheng Chiou menggunakan MPPT, bahwa MPPT adalah pelacakan daya dengan pendekatan gradien (GA). Dan B. Boukhezzar, H. Siguerdidjane [3] terus melakukan kontrol nonlinear dengan kecepatan angin turbin angin DFIG. Kontrol optimal telah diperkenalkan oleh $\mathrm{M}$. Steinbuch, W.W. De Boer, O.H. Bosora, S.A.W.M. Peter, J. Ploeg. Perbaikan mereka masih belum menunjukkan respon dinamis kepuasan pada subjek riak. Dan generasi ketiga dibutuhkan pengendali logika fuzzy. Pengontrol logika fuzzy adalah satu controller yang digunakan untuk memperbaiki respon dinamis sesuai imajinasi Anda terhadap perawatan sistem. Andrea Dadone, Lorenzo Dambrosio memiliki teknik kontrol logika Estimator berbasis adaptif fuzzy dalam sistem generator turbin angin logika fuzzy untuk aturan dasar agar bisa mencapai biaya minimum. Mohamed Thameem Ansari, S, Velusami mengenalkan artikel DMLHFLC (kombinasi linguistic hedge fuzzy logic controller) pengendali ke sistem tenaga hibrida diesel angin diesel dengan BES (penyimpanan energi baterai) dan menjaga kerugian energi. Pengontrol logika fuzzy input ganda dapat ditemukan pada sltankrule tmatlab 701 dan memperhatikan Ying and manual Programming, dengan kinerja dinamis menunjukkan riak yang tereliminasi, namun untuk mencapai settling time terbaik memerlukan adaptasi parameter output dari dual input fuzzy logic controller. Adaptasi parameter output adaptasi Dual Input Fuzzy Logic Controller (ADIFLC) dual input fuzzy logic controller digunakan untuk mengubah fungsi keanggotaan parameter output untuk mencapai settling time terbaik.

\section{Obyek}

Pendahuluan memberitahu kita tentang riak yang selangkah demi selangkah dihilangkan dari tindakan kontrol konvensional, kombinasi tindakan kontrol konvensional dengan numerik, pengontrol logika fuzzy dan fungsi input ganda pengendali puncak logika fuzzy dengan adaptasi parameter keluaran dapat menghilangkan riak dan juga dapat mencapai Waktu terbaik untuk menetap Yang terakhir adalah fungsi triple input membership fuzzy logic controller yang lebih baik daripada fungsi keanggotaan input ganda dengan adaptasi fungsi parameter keanggotaan out, riak yang dieliminasi dan waktu penyelesaian waktu terbaik.

\section{Sistem pengaturan}

Respon dinamik sistem kontrol terjadi ketika pengendali bertindak untuk meredam gangguan terhadap kondisi stabilitas. Secara logika, jika gangguan tersebut terjadi pada kondisi stabilitas maka pengendali akan bertindak menurunkan sinyal sampai kondisi stabil, sebagai sebaliknya jika gangguan tersebut terjadi pada kondisi stabilitas rendah maka pengendali akan bertindak meningkatkan sinyal terhadap stabilitas. Jika kondisi tersebut terjadi maka respon dinamis menunjukkan osilasi mendekati kondisi stabilitas seperti pada gambar 1 . 


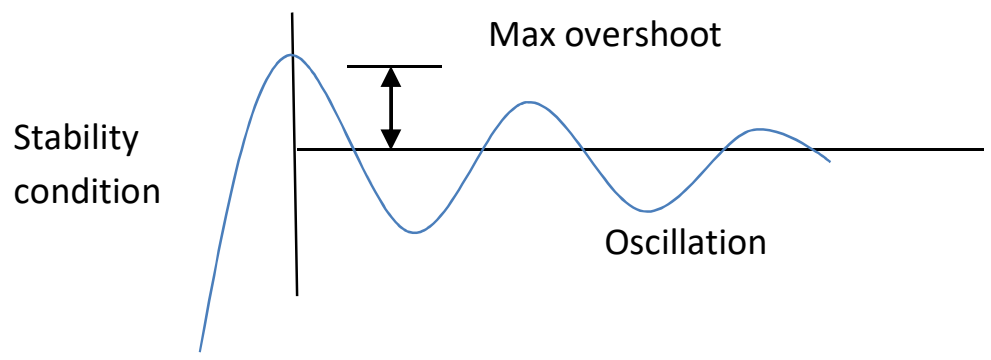

Gambar 1 Respon Dinamis

Kondisi osilasi terjadi karena pengendali terlambat mengantisipasi respons gangguan. Keterlambatan terjadi, diketahui kapan gangguan tersebut tersedia. Tindakan kontrol sebelum fungsi keanggotaan masukan ganda masih memiliki penundaan. Sungguh, ia memiliki riak. Setelah itu, fungsi keanggotaan masukan ganda bisa diatasi dengan riasan yang dieliminasi karena bisa mengantisipasi keterlambatan. Masukan pertama bertindak untuk mengurangi gangguan dan input kedua adalah mengantisipasi penundaan dan untuk penyelesaian waktu terbaik dilakukan adaptasi fungsi keanggotaan output.

\section{Tunda antisipasi}

Antisipasi keterlambatan adalah salah satu topik utama untuk menghilangkan topik riak. Fungsi keanggotaan masukan ganda memiliki dua tugas, input pertama sebagai kontrol kestabilan dan input kedua sebagai antisipasi penundaan. Kembalinya adalah kontrol stabilitas tanpa riak. Meski begitu, fungsi keanggotaan masukan ganda sudah bagus, namun kita tetap mendapat kesempatan untuk meng-upgrade respon dinamis yang lebih baik. Penambahan satu lagi fungsi keanggotaan masukan membuat waktu penyelesaian lebih cepat daripada adaptasi fungsi keanggotaan keluaran. Jadi kita menemukan fungsi keanggotaan masukan tiga kali dalam tulisan ini, seperti terlihat pada tabel 1.

Tabel1 Fungsi tripel input

\begin{tabular}{|c|c|c|}
\hline No & Tipe & fungsi \\
\hline 1 & Input pertama & $\begin{array}{l}\text { Mengatur sinyal } \\
\text { kestabilan }\end{array}$ \\
\hline 2 & Input kedua & $\begin{array}{l}\text { Menghilangkan } \\
\text { osilasi }\end{array}$ \\
\hline 3 & Input ketiga & $\begin{array}{l}\text { Menemuan } \\
\text { waktu tercepat }\end{array}$ \\
\hline
\end{tabular}

Penelitian ini mengatasi kelemahan fungsi keanggotaan input ganda dengan fungsi keanggotaan parameter adaptasi. Jelas, kita bisa melihat tabel 2 tentang studi penelitian.

Pada tabel 2 kita telah ditunjukkan persamaan dan perbedaan fungsi keanggotaan masukan ganda dengan fungsi keanggotaan parameter adaptasi dan fungsi keanggotaan masukan tiga kali lipat. Kesamaannya adalah input pertama dari dua fungsi kontrol yang berfungsi dan menghilangkan riak namun perbedaannya adalah menemukan penyelesaian waktu terbaik dilakukan dengan menggunakan fungsi keanggotaan parameter adaptasi untuk sistem input ganda dan telah dilakukan oleh input ketiga dengan sistem input tiga kali lipat. . Sungguh, tugas mencari waktu penyelesaian terbaik telah dilakukan sistem input tiga kali lebih baik

Tabel 2 hasil riset

\begin{tabular}{|c|c|c|c|}
\hline No & Dua input & Tiga input & fungsi \\
\hline 1 & $\begin{array}{l}\text { Input } \\
\text { pertama }\end{array}$ & Onput pertama & Aksi kontrol \\
\hline 2 & Input kedua & Input kedua & $\begin{array}{l}\text { Eliminasi } \\
\text { osilasi }\end{array}$ \\
\hline 3 & $\begin{array}{l}\text { Adaptasi } \\
\text { output } \\
\text { parameter }\end{array}$ & Input ketiga & $\begin{array}{l}\text { Menemukan } \\
\text { waktu } \\
\text { tercepat }\end{array}$ \\
\hline
\end{tabular}

daripada sistem input ganda. Jadi metodologi diawali dengan pemodelan dual input system, kemudian pemodelan triple input system, dilanjutkan eksperimen, pengumpulan data dan kesimpulan akhir.

Pemodelan

Yang pertama kita mendapatkan tenaga turbin angin yang bisa diekspresikan dengan persamaan (1) dibawah ini:

$$
\mathrm{P}=0,5 \rho \mathrm{U}^{3}
$$

Dimana $\mathrm{P}$ adalah kekuatan angin, massa udara yang spesifik adalah $\rho$ dan $U$ adalah kecepatan 
angin dan tenaga angin yang berubah menjadi torsi dengan ekspresi pada persamaan (2);

$$
\mathrm{P}=\mathrm{k} \tau \omega
$$

Dimana $\mathrm{k}$ adalah perubahan konstanta, $\tau$ adalah torsi dan $\omega$ adalah kecepatan putar. Selanjutnya, daya turbin diubah menjadi tenaga listrik dengan persamaan ekspresi (3);

$$
\mathrm{Pe}=\mathrm{V} \mathrm{I}
$$

Dimana Pe adalah Tenaga Listrik, $\mathrm{V}$ adalah listrik, voltase dan I adalah arus listrik. Pada percobaan kita akan melihat model dan eksperimen.

\section{EKSPERIMEN}

Tujuan utama percobaan ini ingin menunjukkan bahwa input ketiga dari sistem input tiga kali lebih baik daripada parameter output adaptif untuk mendapatkan settling waktu terbaik. Untuk menunjukkan sistem yang lebih baik, kita membutuhkan dua sistem model. Sistem yang pertabia adalah model fungsi keanggotaan masukan ganda dengan parameter output adaptif seperti ditunjukkan pada gambar 1 dan sistem kedua adalah fungsi keanggotaan masukan tiga kali lipat seperti yang ditunjukkan pada gambar 2. Gambar 2 menunjukkan kontroler turbin angin dengan kontroler logika fuzzy yang memiliki dua input yaitu Sinyal kecepatan putar turbin angin dan torsi turbin angin.

\section{HASIL DAN PEMBAHASAN}

Dari percobaan yang digunakan Simulink dari lab tikar 2009a, kita mendapatkan hasil untuk dual sistem 22 detik stabil (gambar 3) dan untuk triple system 16 detik waktu mencapai stabil (gambar 4).

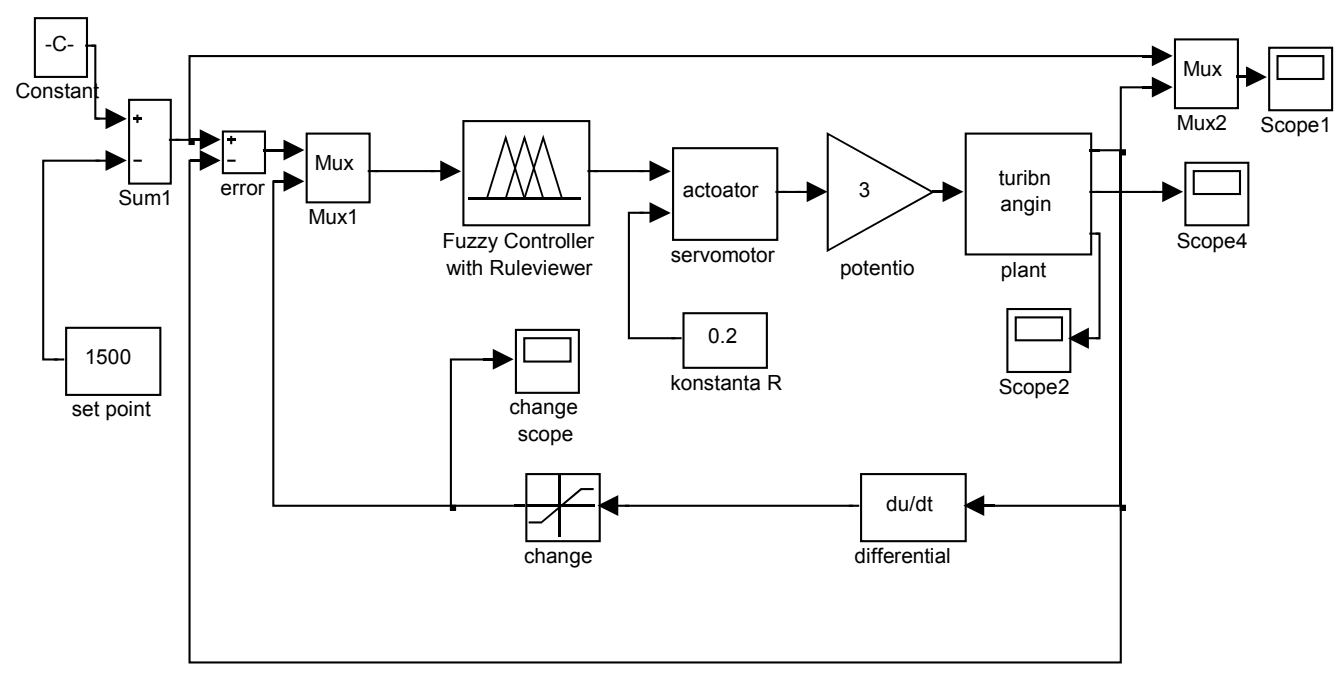

Gambar 2 Dua input FLC

Gambar 2 menunjukkan proses kontrol fuzzy dengan dua input yang terjadi pada model turbin angin dengan dua signal pada mux (multiplekser. Selanjutnya model di running pada program simuling program matlab. Proses dilakuan degan servomotor selama bit 0,2. Selanjutnya dikuatkan oleh potensiometer sehingga signal kontrol fuzzy logic akan diteruskan untuk mengatur turbin angin yang bisa dilihat pada scope 4 . Hasil dari pengaturan turbin angin diumpanbalikkan ke set point untuk mengikuti proses selanjutnya. Hasil grafik fuzzy logic kontroler dua input ini bisa dilihat pada gambar 3. Sedangkan gambar
3 adalah fuzzy logic kontroler dengan tiga input. Proses menggunakan tiga input ini hampir irip dengan proses dengan dua input, hanya bedanya input yang masuk ke multiplekser berjumlah tiga. Tiga buah membership function akan memperbaiki tampilan respon dinamis. Hasil tampilan respon dinamis bisa dlihat pada gambar 4, yaitu grafik kestaiga mabilan yang menunjukkan lebih baik. Hasil grafik pada gambar 4 menunjuan hasil yang sama-sama menunjukan kestabilan tetapi waktu tempuh estabilannya lebih cepat. Hal ini terjadi karena pada membership function yang ketiga 
memberikan tanggapan antisipasi yang lebih responsip dan peka terhadap perubahan penyimpangan umpan balik terhadap set point, hal ini menyebabkan aksi kontrol memberikan teanggapan lebih cepat daripada dua input membership function.

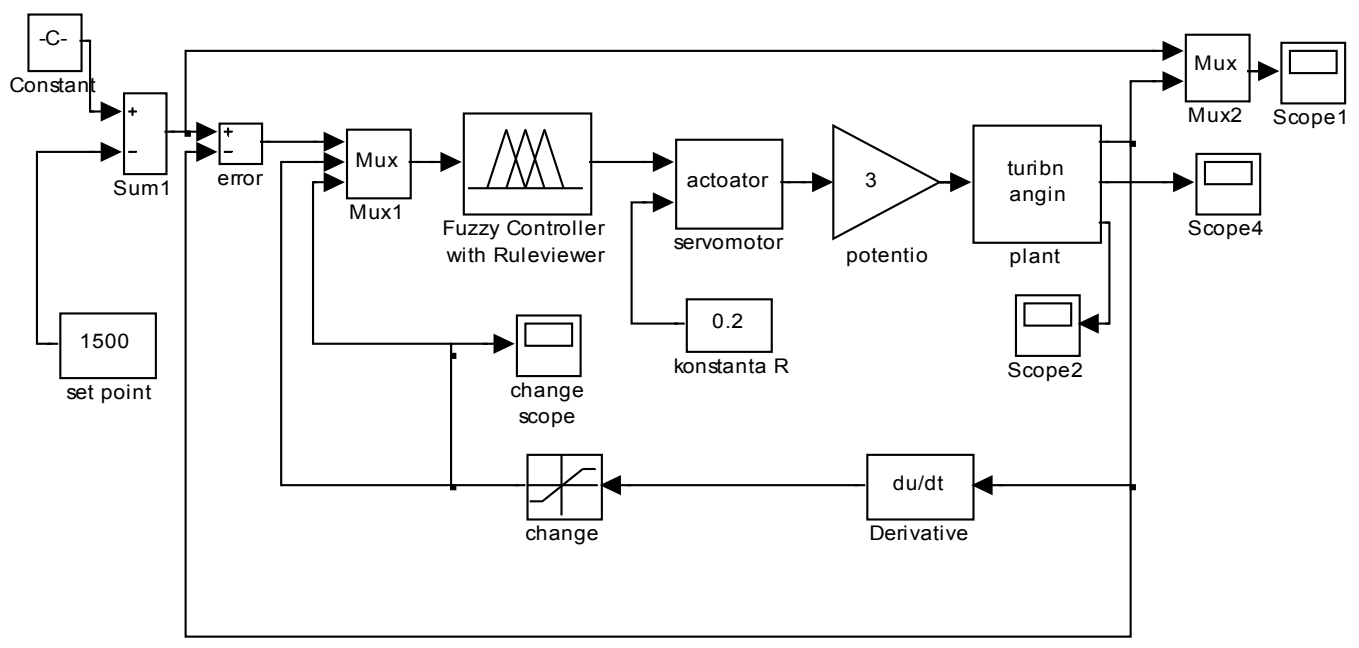

Gambar 3 Tiga input FLC

Seperti ditunjukkan pada gambar 3, gangguan pulsa akan direspon dengan nilai kestabilan dalam waktu tempuh 22 sekon

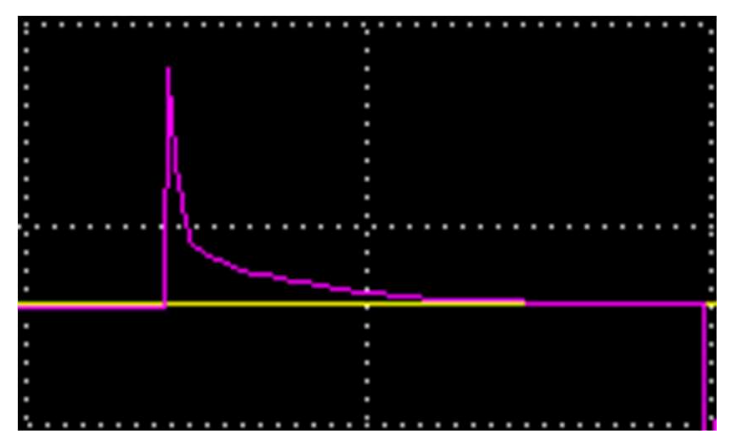

Gambar 4 Grafik dua input FLC

Sedangkan pada gambar 4 menunjukkan hasil waktu mencapai kestabilan 16 sekon.

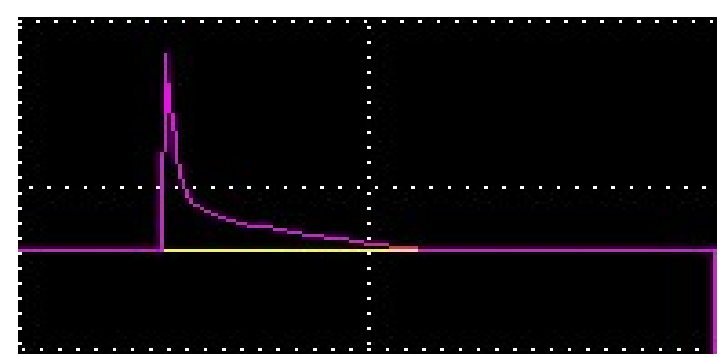

Gambar 5 Grafik tiga input FLC
Waktu kestabilan lebih cepat dengan menggunakan gangguan pulsa yang sama. Ada peningkatan perbaikan reson dinamis jika menggunakan tiga input dibandingkan dengan menggunaan dua input.

\section{KESIMPULAN}

Dari hasil dan pembahasan, dapat disimpulkan bahwa triple input system lebih baik daripada dual input system. Perbaikan yang diperoleh adalah dari waktu mencapai kestabilan 5 sekon menjadi waktu mencapai kestabilan 4 sekon.. secara persentasi berarti mendapat perbaikan 29\%. Peningkatan ini tidak memrlukan instalasi yang begitu sulit, hanya menambahkan input ketiga yang bisa diinstalasi pada pemodelan simulink program matlab.

\section{UCAPAN TERIMAKASIH}

Terima kasih banyak untuk Laboratorium Elektrikal Universitas PGRI Adibuana Surabaya Indonesia yang memberikan fasilitas dan tutorial pemrograman pada penelitian ini. 


\section{DAFTAR PUSTAKA}

Andrea Dadone, Lorenzo Dambrosio, "Estimator based adaptive fuzzy logic control techniquefor a wind turbine-generator system", Energy Conversion and Management 44 (2003) 135-153

B. Boukhezzar, H. Siguerdidjane, "Nonlinear control with wind estimation of a DFIG variable speed wind turbinefor power capture optimization", Energy Conversion and Management 50 (2009) $885-892$

B. Boukhezzar, L. Lupu, H. Siguerdidjane, M. Hand, "Multivariable control strategy for variable speed,variable pitch wind turbines", Renewable Energy 32 (2007) 1273-1287

Kazeminezhad, M. H., Etemad-Shahidi, A., \& Mousavi, S. J. (2005). Application of fuzzy inference system in the prediction of wave parameters. Ocean Engineering, 32, 1709-1725.

Kosko, B. (1991). Neural networks and fuzzy systems, A dynamical systems approach. Englewood Cliffs, NJ: Prentice Hall.

M. Steinbuch, W.W. De Boer, O.H. Bosora, S.A.W.M. Peter, J. Ploeg, "Optimal Control Of Wind Power Plants", Journal of Wind Engineering and Industrial Aerodynamics, 27 (1988) 237-246

M. Mohamed Thameem Ansari, S. Velusami, "DMLHFLC (Dual mode linguistic hedge fuzzy logic controller) for an isolatedwinddiesel hybrid power system with BES (battery energy storage) unit", Energy 35 (2010) 3827-3837

Negnevitsky, M., \& Potter, C. W. (2006). Innovative short-term wind generation prediction techniques. In Power systems conference and exposition (pp. 60-65),

IEEE PES, October 29, 2006-November 1, 2006.

Negnevitsky, M., Johnson, P., \& Santoso, S. (2007). Short term wind power forecasting using hybrid intelligent systems. In Power engineering society general meeting (pp. 1-4). IEEE, 24-28 June 2007.

Ogata, K,'Teknik Kontrol Automatik". Erlangga, Jakarta, 1997

Potter, C., \& Negnevitsky, M. (2003). Short term power system forecasting using an adaptive neuralfuzzy inference system. In Australian and New Zealand intelligent information systems conference (ANZIIS) (Vol. 8, pp. 465-470).

Potter, C., Ringrose, M., \& Negnevitsky, M. (2004). Short-term wind forecasting techniques for power generation. In Australasian universities power engineering conference (AUPEC 2004), Brisbane, Australia, 26-29 September, 2004.

Matlab 7.10.0.499 version (R2010a), Mathworks Inc, USA, 1984-2010

Unimation, Inc., Programming Manual-User's Guide to VAL II (398T1), Version 1.1, August 1984.

Ying-Yi Hong, Shiue-Der Lu, Ching-Sheng Chiou, "MPPT for PM wind generator using gradient approximation “, Energy Conversion and Management 50 (2009) 82-89 